\section{Ensino em Turismo}

\section{Sarah Strachmann Bacal}

Nos sistemas tecnológicos do amanhã - rápidos, fluldos e autoreguladores - as máquina liderarão com o fluxo de materiais nsicos; os homens com o nuxo de informação percepção. Maquinas irão realizar tarefas; os homens, as tarefas intelectuais e criativas. (Toner, 1980:323)

\begin{abstract}
RESUMO: Reflexão sobre o conteúdo e a metodologia do ensino de turismo, abordando três vertentes de formação: "conhecimento de versus "conhecimento acerca de", educadores versus mão-de-obra c "homens de ação". Analisa aspectos da estrutura e características de instituições que objetivam formar formadores de mãode-obra para serviços de base. Conclui destacando a importância, nesse caso, da imagem global do turismo e do acompanhamento das mudanças no mercado de trabalho.
\end{abstract}

PALAVRAS-CHAVE:Ensino em turismo; formação de recursos humanos; instituições.

ABSTRACT:Reflexion about contents and methodology for the teaching of tourism, through a threefold approach: "know of", "know about", educators $x$ workers, "action men". It analyzes some aspects of the structure and characteristics of the institutions which aim to graduate front-line workers trainers. It ends stressing the importance of global image in tourism and of following the work market changes.

KEY IIORDS: Tourism education; human resources. formation; institutions.

\section{Ensino e Formaçāo}

Hoje cm dia, qualquer estudo sobre o conteúdo e a metodologia de ensino para a formação de profissionais nas diferentes árcas de atuação, apresenta-se como uma difícil tarefa. Torna-se mais árida ainda, $\mathrm{cm}$ se tratando de atividades que somente recentemente começaram a ter repercussões nos indivíduos c na socicdade como um todo, quer sob a perspectiva sociológica, quer sob a cconômica. Este ć o caso do cnsino do Turismo.

Para compreender qual seria a melhor mancira de abordar o ensino do Turismo dentro dos parâmetros considerados qualidade total, é preciso que se reflita sobre três aspectos da sua realidade atual para que se possa, num recorte da atividade turística, aplicar conceitos pertencentes a outras árcas do saber que irão esclarecer qual seria o problema com o qual se defronta. Uma vez compreendido o campo da problemática com todas suas variáveis c isolado o problema, ter-sc-á mais facilidade em colocar o assunto de modo mais claro.

\section{Vertentes de Formaçāo}

\section{"Conhecimento De" versus "Conhecimento Acerca De"}

L'ma primeira vertente leva aos tipos "fundamentais de conhecimento" considerados por James (s.d.) e outros: "conhecimento de" c "conhecimento acerca de". Utiliza-se essa classificação (sem fidelidade para com seu sentido original), apenas interpretando cssa distinção; ou scja, colocando suas premissas a serviço de nossa análise. Assim tem-se o que se destaca a seguir.

\section{"Conhecimento De"}

Quanto maior o número de relaçõcs que sc pode perceber entre o objeto formal ${ }^{2} \mathrm{c}$ os outros que o cercam, pode-se fazer com que apareçam as similaridades e as diferenças entre eles. Com isso quer-se referir às áreas do saber que se encontram subjacentes ao conhecimento "teórico"” de nossa análise. É o conhecimento resultante da investigação cientifica c sistemática, que se baseia na observa§ão verificada c reverificada, podendo, na medida $\mathrm{cm}$ que transforma fatos $\mathrm{cm}$ dados, ser comunicável. É o conhecimento que saindo dos "particulares" através da abstração $\mathrm{c}$ da generalização chega aos conceitos, às leis e às tcorias. Estc tipo de conhecimento atingindo um alto grau de precisão c e.vatidão, consegue ser um

\footnotetext{
2. Os objetos podem ser analisados de duas maneiras: o objeto real é a apropriação total de sua essência; o objetoformal é a abordagem especifica de seu estudo

Refere-se a teoria que resulta do contato com a realıdade, da abstração de suas contingências e da generalização do que
} Ihes é essencial. Assim fazem-se leis que irão se encaixando nos alvéølos da trama teórica

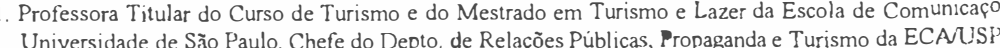
4331 . 
conhecimento dos "universais", que cxpressa conceitos e raciocínios $\mathrm{em}$ proposições e argumentos. Por essa razão o conhecimento cientifico teórico pode transmitir conhecimentos, pois, sendo formado por conceitos, ć comunicável e permite a análise das realidades concretas particulares distintas.

Assim, de posse desse conhecimento quando da resolução de diferentes problemas sabe-se não só o como fazer, mas também, o que, o quando e o onde fazer.

\section{"Conhecimento Acerca De" (ou Para)}

É o conhecimento que busca soluções para os "particulares", é o conhecimento adquirido mediante a manipulação da realidade concreta individual. E um conhecimento demonstrável, porém não tendo sido sistematizado em termos universais não é transmissivel por palavras, ou seja, pode-se narrar uma cxperiência, mas ela será sempre a cxperiência de um singular que não pode ser generalizado. É este o conceito comum da técnica. Por mais analogia que tenha com outro singular não comporta, necessariamente, as mesmas soluções. É um conhecimento individual, é uma fusão de uma longa série de experiências que não pode, portanto, ser comunicado de um indivíduo para outro somente por pronunciamentos verbais. É preciso "mostrar", desenvolver as habilidades de desempenho. Isto significa treinamento, ou seja, o manuseio das coisas. As técnicas quando sofrem um tratamento científico, alcançam o nível de tecnologia.

Este treinamento - conforme o nível de formação almejado - deve ser acompanhado de maior ou menor grau de quantidade de conhecimentos tcóricos. Uma coisa é certa: é imprescindivel nesse tipo de conhecimento estabelecer treinamento! Sempre está-se adquirindo um conhecimento "acerca de", quando se cstá manuseando a realidade, fazendo para saber como se faz. No caso da pesquisa científica, este conhecimento ć baseado em conhecimentos das idćias que constituem a estrutura lógica do conhecimento sistemático. Mas, enquanto manipulação da realidade ć um conhecimento "prático". A análise de seus resultados c as inferências que se pode fazer é que incorporarão o conhecimento científico.

Em relação ao Turismo, é preciso formar núcleos multiplicadores de conhecimento, que por um lado, pesquisará a realidade para inovar ou consagrar conhecimentos já cxistentes. Esses núcleos multiplicadores dos conhecimentos são chamados atualmente, "incubadoras"

A vantagem do conhecimento "real" dos fatos ser calcado em conceitos e en uma ordem lógica, está na evidência de que a ordem conceitual torna inteligívcl a ordem real c, na medida em que se pode sair das hipóteses e chegar às leis, consegucse criar da ciência.

4. Uma nova perspectiva organizacional: "As incubadoras de empresas de base tecnológica em ambiente universitírio.O trabalho aborda aspectos relativos à capacitacão e aprendizagem tecnológica e à transferência de conhecimentos das 1995)
Formadores versus Mão-de-Obra

Uma segunda vertente recai sobre oensino do Turismo. É preciso classificar as diferentes instituições educacionais segundo os objetivos que pretendem alcançar, ou seja: qual o nível de profissionais que pretendem formar? para quais funções deverão estar habilitados? Sob esse ponto de vista, pode-se agrupar as instituições educacionais em duas classes: formadores e mão-de-obra.

\section{Formadores}

As que objetivam formar pessoas capazes de transmitir conhecimentos, não só do turismo como fenômeno, mas também, do turismo como produto, como oferta. $\mathrm{O}$ conhecimento dos mercados real e potencial, dos motivos das viagens, requer o conhecimento das ciências que embasam a teoria da atividade turística, entendida esta como um tipo de comportamento humano, como um fenômeno social de massa e também como atividade econômica. É nestas instituições que podem emergir modelos para organização de empresas, de planificação de políticas turísticas, de consultorias para pequenas empresas, assim como orientação para o desenvolvimento de empreendimentos em locais com vocação turística (atrativos naturais, culturais $^{5} \mathrm{c}$ disponibilidade de recursos humanos).

A função deste tipo de instituição, é formar formadores. Para isso ć necessário criar currículos condizentes com este objetivo, que tenham disciplinas que transmitam conhecimentos sobre ciências do comportamento humano: Psicologia, Sociologia e Economia e um conhecimento sólido de Geografia, História, Antropologia Cultural (Folclore), Administração e Marketing. Com isto, tais instituições colocarão no mercado de trabalho uma mão-de-obra qualificada. Estas matérias devem ser vistas de um ponto genérico, mas, com ênfase no contexto no qual, mais provavelmente, os formados irão atuar

Junto a uma prática, para estar dentro da realidade e também para aplicação das tcorias adquiridas, são os "conhecimentos de", que devem ser transmitidos nos Cursos Superiores de Turismo, que visam primordialmente a formação de formadores.

\section{Mão-de-Obra}

As que objetivam formar mão-de-obra capacitada a atender às necessidades dos setores produtivos, de transformação e de prestação de serviços.

Este tipo de instituição apresenta-se em diferentes âmbitos, desde aquelas que devem formar cxecutivos de alto nível até aqueles que precisam formar recursos

\footnotetext{
5. Os atrativos culturais podem ser de ordem artistica ou histórica.
} 
humanos para a infra-estrutura do sistema turístico. De qualquer modo pode-se dizer que o treinamento nestes casos é imprescindivel O que irá diferenciar o nivel das instituições é o quantum de conhecimento teórico deve ser adquirido a prior do treinamento. Para certos níveis de prestação de serviços, as pessoas ao repetir as fases de uma tarefa, vão formando em sua mente uma espécie de modelo que irá aperfeiçoando e se firmando na mente até atingir um estrutura organizada. Scria um modus fasciendi, como que uma "teoria" particular. Para esse tipo de aprendizagem não ć necessário uma transmissão de conceitos a priori c sim um treinamento supervisionado das tarefas a serem cxecutadas.

Quanto mais clevado o nível das tarefas a serem realizadas, e, conseqüentemente, maiores as responsabilidades das decisões tomadas, mais conhecimentos "universais" se fazem necessários. Os executivos, sejam de hotelaria, de transporte, de agência etc., necessitam uma formação teórico-prática, que deve ser adquirida nas Faculdades c nos estágios $^{6}$ - estágios estes que precisam obrigatoriamente fazer parte dos curriculos.

\section{"Homens de Ação"}

Uma terceira vertente diz respeito aos "homens de ação", termo que se refere aos indivíduos que ocupam importantes cargos públicos, nas secretarias ministérios de turismo etc. Estes deveriam cstar capacitados, mediante conhecimentos adquiridos em instituições superiores específicas de ensino do turismo, a reconhecer a importância dessa atividade no mundo atual e aprender a fazcr uma programaçãoturística, naqual os programas de uma política turística conseguissen maximização dos beneficios que esta atividade pode trazer consigo e minimização dos custos sociais e econômicos.

\section{Questōes que se Impōem}

Como as instituições que objetivam "formar formadores" de mão-deobra para serviços de base, em qualquer área do turismo devem ser estruturadas? A resposta é simples: a análise das funções especificas e das tarefas que lhe são inerentes dão informações sobre que tipo de aprendizado deve ser obtido e o que deve ser ensinado para que se forneça ao aluno a possibilidade de manuseio das coisas c realização de tarefas, tudo isso supervisionado pelos formadores que

\footnotetext{
6. Os estágios devem ser feitos em um tempo longo (no minimo de seis meses), na área escolhida pelo aluno. No final o aluno deve apresentar um relatório como trabalho de conclusão de curso. Este relatório poderá ser substituido. por exemplo, por um projeto sim lado de abenura e/ou fancionamento de una enpresa, inclusive com sos respectivos custo analise da viabilda roteiro completo (elaboração, cotização, comercialização, operação e avaliação) seria uma medida interessante do aproveitamento do aluno no estágio.

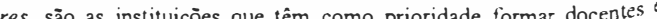
pesquisadores.
}

tenham sobre essa realidade especifica conhecimento teórico/prático. O conhecimento sintético que se incorpora ao aluno no decorrer do manuseio leva ao conhecimento de suas potencialidades.

Ouais as características e tempo de duração de um curso desse nivel? Essa informação será obtida através do cruzamento c análise de três variáveis: as características das funções c tarefas, o nível médio cultural da mão-de-obra potencial existente na área e a duração média dos cursos análogos $\mathrm{cm}$ outras regiões.

O que foi dito para o nível primário é válido para outros níveis. Porém, $\dot{e}$ preciso acrescentar algo nas instituições universitárias que têm por objetivo formar formadores para as instituições educacionais de turismo. Ao enfocar a problemática da formação de recursos humanos para oturismo, deve-se lembrar que existe uma característica muito particular do produto turístico final. Este é, na realidade, um composto de pelo menos, três sub-produtos: agências(operadoras), hotelaria e transporte, que se substancializam numa só imagem turística. Uma agência "vende" uma imagem do "contexto", a hotelaria coloca um tipo de hospedagem conforme um contexto específico c o transporte irá adequar os meios ao contexto onde transita. Estas três atividades compõem, numa visão macro, a atividade turística; estão intrinsicamente interrelacionadas, porém suas organizações cmpresarias são estruturadas, organizadas c administradas diferentemente Esta especificidade coloca nas institutuições de ensino uma grande responsabilidade na imagem do produto turístico, pois deve enfatizar a necessidade de formar pessoas responsáveis pela imagem global do turismo.

Outro ponto importante é acompanhar as mudanças que ocorrem aceleradamentc, na realidade do mercado de trabalho: é preciso que as instituições pensem nas mudanças ocasionadas pela informática, preparando a mão-de-obra para uma concorrência que virá com a globalizazação:

... as empresas precisam criar condiçōes para sedimentar a experiência de gestāo interna da tecnologia, além de promover a aquisiçāo e a incorporaçāo de informaçōes e conhecimentos especializados. Embora a inovaçāo tecnológica concretize-se no àmbito da empresa, ela depende das relaçōes estreitas com instituiçōes de pesquisa para a formação de recursos humanos qualificados... (Maculan \& Baêta, 1995).

\section{Conclusāo}

Saber "o quantum" de conhecimento prático (trabalhar sobre o concreto) e o "quantum" de conhecimento teórico (trabalhar com idéias, conceitos simulações) exigidos pelas diferentes funções que os formados irão desempenhar, dará os currículos corretos para os distintos níveis que se quer formar

As instituições educacionais cumprirão scu papel social, na medida em que poderão fornecer clementos mais capazes para fazer plancjamentos, pesquisas c análises sobre a realidade dos componentes da atividade turística. Por outro lado, darão suportc aos teóricos que nortcarão as mudanças no conhecimento turístico, a fim de adequar continuadamente os resultados obtidos à dinâmica da realidade. 


\section{Concluindo, cita-se um trecho do trabalho de Maculan \& Bacta (1995):}

Para criar (...) a capacidade de inovar, é necessário organizar uma dinàmica de aprendizagem que ocorre na base de uma ampliaçāo das capacidades materias de produçāo com a acumulaçāo permanente de conhecimentos, habilidades e competências, incorporadas nos individuos e nas empresas(...). Embora a inovaçāo tecnológica concretize-se no àmbito da empresa ela depende de relações estreitas com instituições de pesquisa para formaçāo do recursos qualificados (...).

\section{BIBLIOGRAFIA}

MACULAN, Anne Marie D.; BAÊTA, Adelaide Coelho. 1995. Uma nova perspectiva organizacional As incubadoras de empresas de base tecnológica. In: Assembléia do CLADEA. A nais. São Paulo, FEA-USP.

PARK, E.Robert. 1972. A noticia como forma de conhecimento. In: MElOS de comunicação de nıassa. São Paulo: Cultrix.

JAMES, William (s.d.). The principles of psychology. Nova York: Holt. 